\title{
Exploring Quantity and Diversity of Informal Digital Learning of English (IDLE): A Review of Selected Paper
}

\author{
Nofita Sari Gowasa ${ }^{1}$, Ratih Saltri Yudar ${ }^{2}$ \& Mutia Sari Nursafira ${ }^{3}$ \\ ${ }^{1}$ Universitas Negeri Medan, Indonesia \\ ${ }^{2}$ Universitas Riau, Pekanbaru, Indonesia \\ ${ }^{3}$ U-Raise Academy, Pekanbaru, Indonesia \\ mutyasari75@gmail.com
}

\begin{abstract}
ARTICLE HISTORY
Received : 2019-05-03

Revised : 2019-06-15

Accepted : 2019-07-05
\end{abstract}

\section{KEYWORDS}

English digital learning

IDLE Quantity and Diversity

EFL learning outcomes

\begin{abstract}
This article reviews research on Informal Digital Learning of English (IDLE) that has expounded the field of English Language Teaching (ELT) to lead towards Computer-Assisted Language Learning (CALL), focusing on the paper written by Hong Kong University scholar Ju Seong Lee (2019) entitled "Quantity and Diversity of Informal Digital Learning of English." This present paper uses descriptive qualitative analysis in an attempt to address the gap how the quantity and diversity of IDLE genuinely relate to the generally desired outcomes of English learning, and how IDLE activities can make a unique contribution to the discourse of research on the English language and create results from EFL learners from the researcher's perspective. Lee uses hierarchical linear regression analysis to show that IDLE Quantity, Age, and Major are significant predictors of two affective variables (Confidence and Pleasure), while IDLE Diversity and Major significantly predict productive language outcomes (speaking and vocabulary knowledge), scores in standard English Test (namely TOEIC), and lack of one highly influential variable (anxiety). This present article aims to review and discuss the findings, as well as the strengths and weaknesses found in Lee's paper. The article Lee made seems to possess a clear flow on how to explain these two types of education and made the discourse easy to understand. Therefore, the replication of Lee's research should be easy enough for similar research purposes.
\end{abstract}

\section{Introduction}

Lee's 12-page 2019 article is about Informal Digital Learning of English (IDLE) that is currently "the hots" in the field of English Language Teaching, considering it emphasizes Computer-Assisted Language Learning (CALL). Lee's paper claimed digital technology has significant potential to be used by L2 learners learning outside the classroom because more researchers such as Teaching English to Speakers of Other Languages (TESOL) and CALL practitioners are interested in IDLE-oriented topics in various EFL contexts, particularly many scholars in Denmark, Sweden, France (Chik \& Ho, 2017; Lai , 2017; Sundqvist \& Sylvén, 2016; Richards, 2015). This research aims to describe how IDLE's quantity and diversity can make a unique contribution to the results of EFL learners' English proficiency. So, the authors say it makes Lee's article intriguing to discuss because it examines IDLE used by TESOL and CALL practitioners in teaching English to speakers of other languages (L2) and comparing an IDLE with the nonIDLE person.
The authors say in this web 2.0 era, digital technology is increasing, and the developing sophistication of digital technology nowadays makes it easier to learn other languages with various methods. "The Age of Web 2.0 is an appropriate term embedded to represent that students no longer depend on single textbooks, classical texts, or essays. People can create an online community that offers interesting implications for the learning process" (Peters, 2009: 10) (p.3). IDLE, in particular, provides guarantees for everyone who learns their second or third languages digitally.

Previous studies that discussed IDLE activities indicate that EFL students gain a significant improvement in vocabulary, reading comprehension, listening comprehension and school grades (Jensen, 2017; Sundqvist \& Wikström, 2015). Another IDLE study has reported evidence of mixed benefits in IDLE activity (Olsson \& Sylvén, 2015). There are some recent studies (Lee \& Dressman, 2018; Lai, Zhu, \& Gong, 2015) that have paid attention to the diversity of IDLE activities that are conducive to achieving the desired results of English language 
learning, such as self-confidence, productive vocabulary knowledge, speaking and scores on formal testing in the English language.

This paper tries to address any scepticism on IDLE activities. The authors, in particular, are still not convinced to what extent the diversity of IDLE activities used by EFL students relates to the results of learning English. This review article observed this gap and tried to explore this less mapped terrain by aiming to increase the readers' understanding of the quantity and diversity of IDLE activities related to the results of English learning. This paper's findings also offer new insights on research issues that may help education stakeholders (e.g., institutions and teachers) in making informed decisions about curriculum designing and teaching.

\section{Method}

The method that this paper used in this review article is qualitative descriptive, which provides an overview and analysis of Lee's article that used a quantitative approach using a questionnaire. The research in this article is to investigate the practice of IDLE among Korean EFL students, whose data are from 317 students and different universities. There are around three separate universities, the lee's paper did not mention the real names of the three universities in Korea, but he gave pseudonyms from the three universities, aliases of the University are Korea Western University (KWU), Korea Eastern University (KEU) and Korea Central University (KCU). After receiving permission to collect data obtained from the three universities, the data sources were nine instructors and survey participants.

In Lee's paper say that previous studies have reported that foreign experience can significantly affect the state of anxiety and abilities of Korean English students. Therefore, this research is only for students who have never lived or studied abroad to reduce potential confounding variables. Lee's paper took data from 71 Korean EFL students who had no experience abroad. In this research the average age studied was from the ages of 19 to 26 and the various years of student lectures starting from the first year, second, third and fourth years both men and women where this study took data from multiple majors such as education English, English literature, humanities, engineering, and others. And most of the students have studied English for more than six years.

\section{Strengths}

The authors say Lee's article clearly describes the quantity and diversity of IDLE and has a title that strongly reflects the content, and the title synchronized well with the abstract, which is written as a seemingly perfect summary of the entire research article of Lee's. The keywords are appropriately narrowed, so it is easy to know what points are discussed in this study. And in this research of the lee's paper, the tools used are questionnaires which are quite easy to use by the research subjects so that the data collection does not take a long time because when retrieving the data directly it is obtained and can be recorded or included in the study. As well as easy to manage because students can complete the test within 10 minutes and use their own digital devices in the class and test scores, which are automatically viewed after being submitted to the questionnaire.

This paper of Lee's article makes it easy for EFL students to acquire a second language (L2) which in technological advancements in the current web 2.0 era or the millennial era is now comfortable with the ever-growing digital all people can quickly learn English outside class, and they get the potential from it. Therefore, with the increasing number of informal digital learning in English outside the classroom (IDLE), it makes increasing researchers and practitioners in the field of English language teaching to speakers of other languages (TESOL) and the help of computer language learning (CALL). Lee's paper say discusses the four dimensions of knowledge because of the increasing interest in understanding language learning in out-of-class CALL settings (i.e., IDLE). Benson (2011) proposes four aspects of L2 learning outside the classroom in terms of formality (is the language learning experience structurally formal and certificate given. For example, formal, non-formal, or informal), location (where language learning occurs physically: for example, in the classroom, outside the classroom, extracurricular, and outside of school), pedagogy (the extent of learning formal language processes are involved: for example, self-instructed, and naturalistic), and locus of control (the scope to which language learners control their learning; for example: independent or directed).

In his paper, we can find out that "digital learning contributes quantitatively to teaching and learning interactions outside the class" (Shearer, 2003) (p.17). This is apparently because the new generation seems to be very interested in the digital tools they use because they have diversity in the learning process and help prepare themselves for the future (Solomon \& Schrum, 2010: 1) (p.2). Yamamoto et al. (2010: 109) provided support with the statement that teaching from a web-based teaching perspective needs to be examined as the way a teacher teaches, then how students learn and cultural bases. In the field of Computer Assisted Language Learning (CALL) a researcher examines the impact of technology integration on teaching and learning English as a second language (ESL) and English as a foreign language (EFL) (Frigaard, 2002; Al-Mekhlafi, 2006; Timucin, 2006). Carefully process the implementation of an EFL innovation in the form of CALL and TESOL in the preparation program at the Korea University Timucin (2006) (p.4).

The authors say his research offers new insights into the problem and helps education stakeholders 
(e.g., Institutions and teachers) make informed decisions about curriculum and design learning. And this second language digital learning refers to digital devices (e.g., smartphones, tablets, computers, laptops and devices etc.) and there are also a variety of resources used (e.g., MP3s, web applications, social media, YouTube, etc.). S.o that the presence of digital devices and resources through the development of technology today can have a positive impact on users of digital technology and build students' creativity in creating innovations in learning. In this study also not only discusses the tools and resources of digital technology but also discusses document certification so that one's competence is given by an accredited or official institution and recognized by other employers' agents. From this IDLE learning in an extracurricular context it gives responsibility to students to be able to be independent in completing their homework through (e.g., Wikipedia articles or watching YouTube tutorials) prepared by the teacher (Semistructured) to assess student performance. Moreover, in IDLE, there is unstructured learning that is the initiative of students in getting more lessons or improving their English skills by chatting casually through Facebook and other social media to socialize.

The comparison between the quantity and diversity of IDLE, which has a positive impact on English learning, has reported a positive correlation between L2 learning outcomes and the number and diversity of IDLE. Over the past decade, several studies have reported a positive relationship between the number of IDLE activities and L2 learning outcomes such as vocabulary knowledge, reading and listening, and school grades (Jensen, 2017; Olsson, 2011; Sundqvist, 2009; Sundqvist \& Sylvén, 2014; Sundqvist \& Wikström, 2015; Sylvén \& Sundqvist, 2012).

Therefore, these studies consistently suggest that frequent involvement with IDLE activities (e.g., digital games) is positively correlated with L2 learning outcomes among young EFL students in the Nordic region. Other recent studies (e.g., Lai et al., 2015; Lee, 2017; Lee \& Dressman, 2018) have emphasized the importance of the diversity of IDLE activities. For example, Lee (2017) and Lee and Dressman (2018) show that EFL students who involve themselves in various IDLE activities and who achieve a balance between forms and activities that focus on meaning can create a healthy IDLE ecology that leads to positive language learning.

\section{Results}

These studies found that various types of IDLE activities can increase affective variables (lack of anxiety and self-confidence), productive language results (productive speech and vocabulary knowledge), and scores in standard English language tests (TOEIC).
It is clear that in Lee's research for collecting data using one questionnaire, six English language learning results, semi-structured interviews, and a list of the first questions (demographic information) regarding school background, class, gender, department, experience and length of time studying English. The second question (the results of learning English) to obtain the psychological aspects of students from the level of English such as selfconfidence, enjoyment and anxiety as well as English standard skills (TOEIC score). Then the third question (number of IDLE activities) such as on average, how many hours per day do you spend involved in IDLE activities outside the classroom in the past six months? Uniquely in this article. After the learning outcomes were discovered, the researchers conducted semi-structured interviews to verify students' quantitative responses, deep understanding of their questionnaire responses and to gain a diversity of IDLE activities. After that there was an actual result that the number of IDLE experiences was: $62.0 \%(\mathrm{n}=$ 44) students spent less than one hour on IDLE practice every day, followed by $22.5 \%(\mathrm{n}=16)$ who consumed between one and two hours, and $15.5 \%$ (n $=11$ ) who spent more than two hours. And descriptive information about the diversity of participants' IDLE practices. Overall, students involved eight different IDLE activities that combined the activities of FFI and MFI.

In Lee's paper, there are determinations of English learning outcomes such as the standardized English language skills (TOEIC score), psychological aspects of students related to their level of English (beliefs, enjoyment, and anxiety), and productive language (speaking and vocabulary). After assessing the results of the determination of these three things, the authors believe that Lee has unveiled the existence of a more holistic understanding of student language skills. The authors say that the determination of the results of learning English makes students more enthusiastic about learning and having high motivation to get high scores so that they can accelerate their ability to learn English. In Lee's paper to get data about selfconfidence, enjoyment, anxiety, and TOEIC scores obtained from the questionnaire and to speak, investigators gave 5 minutes of an English language oral test to each participant. Just like the IELTS speaking test, this test is interactive. After being told about the goals, instructions, and the total duration of the test, Lee's research required the participants to talk about their personal opinions and memories of topics such as hobbies, food, and motivation to learn English. For example, "Tell me about one of your hobbies," or "What is your motivation for learning English?" Student responses are recorded for the next rank. Three English language assessors (one certified assessor and two experienced English teachers) were recruited to evaluate all speaking samples based on the modified TOEFL Speaking Rubric. There are short training sessions (e.g., practical assessment 
meetings and checks for internal reliability) before the actual evaluation. The authors say that getting the data is very good because, for example, in the speaking test using the IELTS speaking test, so students already know and practice how IELTS speaking tests so that later students are no longer confused if they want to continue their education abroad using the IELTS test. The participants speak of their personal views in learning English using digital technology, so their ever-evolving perspective made the development of learning using IDLE increase more reflective. What the authors would like to note is Lee's attachment to the semi-structured interview and interview guide, which is a great insight and convenience for fellow researchers and practitioners. At the tail end of Lee's paper, he explains about himself briefly and does not forget to thank the journal editors and anonymous reviewers.

\section{Weaknesses}

The advantages of Lee's paper, it certainly has some disadvantages, namely, L2 learning activities outside the classroom (IDLE) are not very effective. Why? Because a teacher cannot provide qualitative findings that describe how students activate or participate in various IDLE activities, even in this IDLE activity those who do it may not be themselves but have their friends or relatives do it because not all students like IDLE learning. So that it does not convince the actual number and diversity of English learning in IDLE.

Then the authors say in this study did not have a digital learning strategy, if you have a learning strategy, then this research will be better because later everyone can try it and try to improve their English language skills. There is a lack of invitation for readers to advance technology to succeed as teachers must effectively implement technological tools in the classroom (Cabanatan, 2003; Li, 2014). As well as the lack of acknowledging the role of teachers in technology-enhanced language teaching, though Lee did introduce eight other different parts, in line with Goodyear (2001), as well as four different teacher roles in line with Berge (1995) and Liu, Bonk, Magjuka, Lee, \& Su (2005). It seems done to analyse the characteristics of good language teachers, especially in technology-enhanced pedagogical frameworks.

From his research tools that are used, the questionnaire cannot all be answered, such as being sent a sheet of paper, not all of them want to be answered, then sent to the link, not all of them want to open. Then in the phenomenon of digital technology that is developing at this time has a lot of adverse effects on people, especially to students, thereby reducing their interest in learning or doing positive things because they are more concerned with digital devices that they use such as playing games and social media regularly, Which makes them complacent and lazy to learn. In particular, meta-analysis studies (Sung et al., 2015; Sung, Chang, \& Liu, 2016) have provided evidence that mobile learning that lasts less than one week does not usually have a significant effect on language skills. It does not give overall positive results to students such as the vocabulary they get in listening not all of them want to refer to the dictionary, but generally, those who do things like that are students who lack interest in learning English.

The authors say there is also a need for certification in IDLE learning to be more secure and reliable in studying $\mathrm{L} 2$, but unfortunately, in this study, the certification issued by Coursera was not recognised by other formal institutions because in this study it was still not valid (p. 2). Apart from the increasing number of literature in IDLE, it still cannot be concluded whether or to what extent the number and diversity of IDLE activities are related to the results of learning English among EFL students. Then the disadvantages in second language learning (L2) in this IDLE are the existence of internet constraints such as non-current networks, short duration, high anxiety so there is no desire to continue learning English through digital. In Lees' paper, it was found that eight students did not take vocabulary tests, so there were eight missing values for PVLT. The Authors say this is a very ineffective thing because in this IDLE there should be many students who are interested in learning the second language because it can be practically practised everywhere and whenever and the more sophisticated digital students have in the 21 st century. In Lee's paper, the number of IDLE experience students spends less than one hour on IDLE practice every day and even more than two hours. The authors judge that the amount of time they spend in IDLE practices is less effective, as indicated by the remaining lack of interest in learning a second language through IDLE, even though IDLE is very helpful in facilitating, and should make learning enjoyable to students and make the learning process to be more efficient (Rusman, 2013: 65). Furthermore, in the results, students' experience in learning the second language through IDLE did not elaborate the times that students use it, whether in the morning, afternoon or evening. Therefore, while IDLE may be praised to be a great tool in English learning, the authors point out that it is still unknown when would be the best times to do IDLE, including where learners would be most comfortable to learn the second language through IDLE.

In his paper, Lee proposes four dimensions of L2 learning outside of the first whether formally structured language learning experiences and certificates are given, second where language learning takes place physically), third (the extent to which formal language learning processes are involved), fourth (the extent of language learners controlling their learning). However, it seems that from these four dimensions, Benso said that the dimension was a 
rather rudimentary framework (p.15). The author says that the proposal for four dimensions was good but, would even better if the framework was improved first to ensure the acquisition of valid data so that the use of IDLE continues to increase, and there is no doubt to obtain valid data so that students are satisfied with the results they get as well as researchers who obtain data satisfied with the data they process is valid and can develop a better diversity of IDLE.

The authors say that using IDLE must be consistent so that students can continue to use it effectively, and with the diversity of existing IDLE, make students continue to be interested in using it so that they can continue to learn effectively and use their time as well as possible. And by consistently applying IDLE, you will get the consequences of the emergence of behaviour about learning English; students show responses, questions or statements given by the teacher (Slavin, 2000: 256). Digital games that are given to make students interested in learning English should be given a time limit so that they are not dissolved in the game.

Then the quantity and diversity that exists in this IDLE are not explained significantly like the example of a game like what is applied in second language learning? Like the opinion of Rusman (2013: 122123) that the game gave must be by the objectives learning, providing rules in the game, the existence of competition, challenges, delusion, security and entertainment to make the lessons they learn are far more effective and enjoyable for students.

What social media do they use to learn a second language? How can it be ensured that they use social media to learn? Then use google translate, is it sufficient for students? How do they use it? Isn't using google translate makes students lazy to think and lazy to use dictionaries? Then is it practical for students? And the authors say findings regarding the relationship between the number of IDLE and the diversity of IDLE do not have valid results.

\section{Conclusion}

This paper about IDLE activities investigates the quantity and diversity in IDLE learning that increases interest and depth of discourse for researchers and practitioners in the field of Teaching English to Speakers of Other Languages (TESOL) and Computer-Assisted Language Learning (CALL) assistance by offering new insights on how to obtain a second language very easy in digital technology that uses web 2.0, which is very rapidly developing in the current millennial era and provides many interesting things in acquiring a second language even though not all have a positive impact on users because not all use digital technology for learning but to play games and play social media. Further, lee's paper says his research using questionnaires to determine the number and diversity of IDLE learning, the questions used by giving a list of the first questions (demographic information) about school background, class, gender, department, foreign experience and length of time studying English.

The second question (the results of learning English) to obtain the psychological aspects of students from the level of English such as selfconfidence, enjoyment and anxiety as well as English standard skills (TOEIC score). Then the third question (number of IDLE activities) such as on average, how many hours do you spend every day involved in IDLE activities outside the classroom in the past six months? And from the questionnaire results although it still has some disadvantages digital L2 learning is still being developed to be more effective in learning L2 so it can be used in any country to make it easier to obtain a second language. Apart from the increasing number of literature in IDLE, it still cannot be concluded whether or to what extent the number and diversity of IDLE activities are related to the results of learning English among EFL students.

\section{Acknowledgement}

The writers give their gratitude to anonymous reviewers and colleague who assisted immensely in the production of this research article, especially for their feedback and critique.

\section{References}

Benson, P. (2011). Language learning and teaching beyond the classroom: An introduction to the field. Beyond the language classroom (pp. 7-16). Palgrave Macmillan, London.

Chik, A., \& Ho, J. (2017). Learn a language for free: Recreational learning among adults. System, 69, 162-171.

Hamuddin, B. (2015). DISCOURSE ON MEDIA: Bringing Hot News into ELT's Classroom Discussion. Proceedings of ISELT FBS Universitas Negeri Padang, 3, 87-95.

Hamuddin, B. (2016). Using Content Analysis (CA) in Seeking the Opportunities for Alumni of the English Department in Newspapers. ELTLectura, 3(1).

Jensen, S. H. (2017). Gaming as an English language learning resource among young children in Denmark. Calico Journal, 34(1).

Lai, C., Zhu, W., \& Gong, G. (2015). Understanding the quality of out-of-class English learning. TESOL Quarterly, 49(2), 278-308.

Lee, J. S. (2019). Informal digital learning of English and second language vocabulary outcomes: Can quantity conquer quality?. British Journal of Educational Technology, 50(2), 767-778. 
Lee, J. S., \& Dressman, M. (2018). When IDLE hands make an English workshop: Informal digital learning of English and language proficiency. Tesol Quarterly, 52(2), 435-445.

Olsson, E. (2012). "Everything I read on the Internet is in English". On the impact of extramural English on Swedish 16-year-old pupils' writing proficiency.

Peters, L. (2009). Global education. Washington, DC: ISTE.

Richards, J. C. (2015). The changing face of language learning: Learning beyond the classroom. RELC Journal, 46(1), 5-22.

Rusman. (2013). Pembelajaran Berbasis Teknologi Informasi dan Komunikasi: Mengembangkan Profesionalitas Guru. Jakarta: PT. Raja Grafindo Persada.

Slavin, R. E. (2000). Educational Psychology: Theory and Practice. Sixth Edition. Boston: Allyn and Bacon.

Solomon, G., \& Schrum, L. (2014). Web 2.0 how-to for educators. International society for technology in education.

Sundqvist, P. (2009). Extramural English matters: Out-of-school English and its impact on Swedish ninth graders' oral proficiency and vocabulary. Doctoral dissertation, Karlstad University).

Sundqvist, P., \& Sylvén, L. K. (2014). Languagerelated computer use: Focus on young L2 English learners in Sweden. ReCALL, 26(1), 3-20.

Sundqvist, P., \& Sylvén, L. K. (2016). Extramural English in teaching and learning. London: Palgrave Macmillan.

Sung, Y. T., Chang, K. E., \& Liu, T. C. (2016). The effects of integrating mobile devices with teaching and learning on students' learning performance: A meta-analysis and research synthesis. Computers \& Education, 94, 252-275.

Sung, Y. T., Chang, K. E., \& Yang, J. M. (2015). How effective are mobile devices for language learning? A meta-analysis. Educational research review, 16, 68-84.

Sylvén, L. K., \& Sundqvist, P. (2012). Gaming as extramural English L2 learning and L2 proficiency among young learners. ReCALL, 24(3), 302-321.

Sylven, P., \& Sundqvist, L. K. (2016). Extramural English in teaching and learning.

Timucin, M. (2006). Implementing CALL in an EFL context. ELT Journal, 60(3), 262-271.

Yamamoto, J. (Ed.). (2010). Technology Implementation and Teacher Education: Reflective Models: Reflective Models. IGI Global. 